\title{
The Multi-dimensional Perspective on Track and Field Course Content Construction
}

\author{
Yanxia Cao \\ Department of Physical Education, Yulin College, Yulin 719000, China. \\ 916490618@qq.com
}

\begin{abstract}
By using the method of literature, questionnaire, mathematical statistics and other research methods of current to our country track and field courses to carry out the current situation investigation and study The results show that: The school sports while recognizing the importance of track and field value, but in the actual development is not satisfactory, analyses that the main reason is the lack of a reasonable track and field courses. Based on this, the author from the new concept of physical education curriculum guide, track and field courses, different itself in the development of school sports thought essential connections and the students physical and mental characteristics and other aspects, combined with a healthy, athletic, interest three school sports thought connotation, explore the reasonable construction of the track and field courses need to open to question, designed for the school sports curriculum construction mentality and the reference.
\end{abstract}

Keywords: Track and field courses; construction; survey.

\section{Introduction}

New curriculum standards promulgated in 2001, changed its name to the original track and field track and field [1], so that the sport of track and field and into sports-related courses, thus broadening our horizons, to build a rational track and field course content provides a platform to better solve the contradiction between the value of athletics in the actual teaching it is difficult to show, but there is no systematic track and field course content. For in this study, the status of this new physical education curriculum content standards of track and field implementation was investigated and analyzed, with the current session of the school sports debate "physical education in health, sports, interest which centered on the question," from examining various angles of Track and Field Course. Construction of process content, to enrich and improve track and field course content, provide a theoretical basis for the construction of school PE curriculum content.

\section{Subjects and Methods}

\subsection{Study.}

Track and Field Courses under the new curriculum standards.

\subsection{Research Methods.}

(1) Literature

Of relevant research literature collation and analysis, this study provides theoretical support.

(2) Investigation

Questionnaire survey and field visits to France, the contents of some provinces and cities of track and field course in the middle school PE status quo investigation and interviews, questionnaires issued to PE teachers 500 were returned 476 questionnaires, 9 invalid questionnaires, the effective rate was $93.40 \%$.

(3) Mathematical statistics

The survey collected data were analyzed with a statistical relevant data using different statistical methods, the main issues to be studied objectively reflect the.

(4) Logical analysis

Construction of the theory from the course, provide a theoretical basis for constructing reasonable curriculum. 


\section{Results and Analysis}

The Impact of Physical Education Course Reform Through the survey found that the majority of sports teachers to implement the new curriculum standards hold a positive attitude, $72.4 \%$ of teachers think that the new physical education curriculum standards more in line with the actual situation of PE teaching in primary, 73.1 percent of educators believe is conducive to the quality of students education, $74.2 \%$ of respondents believe that helping to train students interested in sports, there are $68.3 \%$ of respondents believe that the implementation of new curriculum standards can improve motivation to work. For a long time, PE teachers are accustomed to sports management system to develop a unified national curriculum, uniform syllabus prepared by subject matter experts, the number of hours each year teaching, teaching content, teaching schedule is very detailed, in accordance with the national unified teaching outline of the implementation of Physical Education[1]. The current approach to reform, so that PE teachers to a promising but confused direction, Table 1 shows that $64.2 \%$ of PE teachers in new curriculum standards that because there is a strong operational, but still give their work inconvenience $34.5 \%$ of teachers feel they are not very understanding of physical education and health curriculum standards proposed "five areas", 33.4\% of teachers think that the new curriculum standards can not replace the existing sports syllabus.

Table1 Implementation of the new physical education teacher questionnaire Identity

\begin{tabular}{|c|c|c|}
\hline Order & Survey content & $\begin{array}{c}\text { Recognition } \\
\text { rate }(\%)\end{array}$ \\
\hline 1 & $\begin{array}{c}\text { New curriculum standards are in line with our actual situation of school } \\
\text { sports }\end{array}$ & $72.4 \%$ \\
\hline 2 & $\begin{array}{l}\text { Whether the new physical education curriculum standards of conduct in } \\
\text { favor of quality education }\end{array}$ & $73.1 \%$ \\
\hline 3 & $\begin{array}{c}\text { Whether the new physical education curriculum standards will help } \\
\text { improve students' sports participation }\end{array}$ & $74.2 \%$ \\
\hline 4 & $\begin{array}{c}\text { Whether the new physical education curriculum standards will help } \\
\text { improve teachers' work motivation }\end{array}$ & $68.3 \%$ \\
\hline 5 & New curriculum standards are a strong operational & $64.2 \%$ \\
\hline 6 & You are well aware of the new physical education curriculum standards & $34.5 \%$ \\
\hline 7 & New curriculum standards can not replace the existing sports syllabus & $33.4 \%$ \\
\hline
\end{tabular}

\subsection{Value Contradiction Athletics and Its Actual Conduct Is Increasingly Evident.}

Table 2 Different versions of Track and Field Junior High PE teaching content proportion statistics

\begin{tabular}{c|ccc}
\hline Grade & First & second & Third \\
\hline Press & & & $16 \%-18 \%$ \\
\hline People'sEducation & $16 \%-18 \%$ & $16 \%-18 \%$ & $17.1 \%-21.8 \%$ \\
Zhejiang Education & $19.1 \%-23.6 \%$ & $19.1 \%-23.6 \%$ & $23.3 \%$ \\
Jiangsu Education & $26.6 \%$ & $25 \%$ & $31 \%$ \\
Shanghai Education & $31 \%$ & $28.5 \%$ & \\
\hline
\end{tabular}

PE syllabus (syllabus), the sport of track and field as a basis, as part of the main content compulsory in 2000 issued by the Ministry of Physical Education and Health curriculum standards, PE education shift in syllabus, track and field contents accounted for compulsory $40 \%$ of the class[2]. The author of the survey results also show that the content of an important position of Track and Field in Physical Education and endorsed a number of track and field course content main content accounted for $72.6 \%$ of the total number of the survey, 82.14 percent of the new version of the track and field textbook contains content, the survey only there are $13.57 \%$ of teachers think that the new physical education curriculum standards, track and field content is not important, and that an 
important number of people accounted for 86.43 percent of the survey. Visible in China's sports education, top-down type of content that the track and field has an irreplaceable role in the new curriculum standards prepared textbooks reflects this, I randomly selected high school sports in the textbooks, the track and field the proportion of the content to make a statistical comparison with other content content of Track and Field on average 34\% of the total content of textbooks (See Table 2).

Interviews with relevant experts and sport teachers about class content value Athletics, Track and Field that the economic content, effectiveness is easy to carry, less space is limited by the equipment; can be targeted to the development of students' physical fitness and skills capacity, high security; energy effective students willpower and hard-working spirit; contact with students real life closely, can effectively promote the correct body posture and develop a healthy growth, have a more profound cultural heritage competitive [4]. Although there are many value content of Track and Field, has an irreplaceable role, but in the actual conduct is unsatisfactory, some schools only the content as the content of physical education class track and field preparation stage, there is no full professor of physical education content Track and Field [5].

In the above two contradictory "health first" sports thinking in the student body, with students' interest in teaching-oriented concepts, become apparent. Course of Track and Field have important educational and practical value, but the value is very low utilization of the two, how to resolve this contradiction, it should fit the needs of students? Or mandatory requirements or indoctrination? This is a question worth pondering. Reform of Track and Field Course content like from one extreme to another, at present, desalination projects competitive athletics high voice, a complete denial of the most attractive aspect of athletics - Athletics property, denied property athletics track and field projects is the item blocked[6], at present, only athletics "latent Sports textbooks" in the form, students receive knowledge of track and field is fragmented, broken, making it impossible to reflect the value of education and athletics projects bring Practical value. Has become the essence of athletics track and field games brought results, most of the schools surveyed have undertaken athletics teaching different forms of the game, it will put forward more complete game of athletics recommendations scholars, such reforms Information has been a complete departure from athletics has value and features.

\subsection{The Current Content of Track and Field to carry out the Existing Problems and Analysis.}

The author of "New curriculum standards and the main problem in athletics in open class content present in" questionnaires and site visits. The results show (see Table 3), resulting in one of the main track and field courses student participation is not strong there is no reasonable course content as a carrier of teaching, teaching method is based on rich contents and characteristics of teaching as a basis for teaching innovation; students interested in teaching the value of content and novelty; the lack of venues and equipment can also be eliminated by changing the teaching content. Therefore, the main cause of the above-mentioned problems are: Athletics Course content rebuild issues. Since 2000 various publishing houses have published a different version of "Sports and Health" textbook, basically regarded as the main track and field contents, according to the guidance of the spirit of the new curriculum standards, dilute the concept of competitive projects, the project content transformation reasonably effective improve the feasibility of teaching[7]. Therefore, the need to rebuild the track and field course content according to the actual situation around, and strive to achieve student-centered, to stimulate student interest in learning.

Table 3 Track and Field Courses agree to carry out a problem in the table

\begin{tabular}{ccc}
\hline Order & Survey content & $\begin{array}{c}\text { Recognition } \\
\text { rate }(\%)\end{array}$ \\
\hline 1 & Students participate in awareness, enthusiasm is not high & $79.2 \%$ \\
2 & Lack of Track and Field content teaching and reference materials & $63.1 \%$ \\
3 & Teaching methods are not new, in the form of a single organization, can & $59.5 \%$ \\
4 & not mobilize the enthusiasm of students & $54.3 \%$ \\
5 & Lack of appropriate space, equipment and devices & $50.8 \%$ \\
\hline
\end{tabular}




\section{Thought under New Curriculum Frame Reconstruct the Contents of Track and Field}

The concept of the new physical education curriculum intent to be expressed has been involved in the physiology, education, psychology and other disciplines focus on young students, to ensure that every student benefit[8]. The idea to break the traditional, subject-centered curriculum and community building point of view, attention to student learning process, attention to the emotional experience of students; the concept of the new curriculum standards, the curriculum chosen, must be healthy first as the guiding ideology, from the students 'motivation to start to promote student physical activity awareness raising, while the selected content must be consistent with the physical and psychological characteristics of students, individual attention to students' emotional experience, highlighting the dominance of teachers and students in the teaching process dominant position, track and field content should therefore reflect these four dimensions, the concept of new curriculum standards should be used as building content guiding Track and Field, and plays the role of "guidelines".

New curriculum standards noted [9][10]: the purpose and effectiveness of the reach of the target track and field courses desired. Course objectives special attention to the development of students' endurance quality, students sense of competition and the spirit of unity and cooperation, and not afraid of hardship and tired, indomitable, self-defeat and opponents of strong will. Track and Field Target course content fully reflects the fundamental value of athletics, athletics explained to enhance students' physical fitness plays an important role in a student body have a greater role in promoting development of physical education programs in track and field the contents of the learning process, in addition to focusing on the fitness track and field action, it should also enable students to master certain basic athletics skills and knowledge to improve the students' athletic ability. While paying attention to students interested in track and field training, we can not completely negate the competitive nature of athletics, track and field contents so choose should be based on athletics modeled critical absorbing sports-related projects and track and field.

\subsection{Understand the Nature of Contact Sports Education Thought, Correctly Handle the Relationship between Health, Track and Field Athletics and Interests between the Type of Content.}

Physical features from body motion itself, the body's movement determines the objectivity of sports functions. For the individual, promote health science movement is inherent in sports, the nature of the function, the concept of ideology does not exist, does not reflect the will of the class [11]. From this perspective, every kind of sports ideology must reflect the essential function of the core sports content, if it can not be called away from the ideological and physical education, to reflect the essential function of sport, course content selected must have a certain competitive sex, to promote student health, they must bear some of the load movement and master motor skills, making it a means of physical exercise, track and field course content must therefore have a certain fitness effect (competitive), which is the physical education curriculum Unlike one of the characteristics of other courses, while attention should be paid through the grasp of Track and Field course content targeted to reflect the degree of difficulty and healthfulness. Formation of student health concerns and lifelong sports consciousness has become the main areas of concern School Sports Thought, but the health of students and lifelong sports consciousness must rely on to get a reasonable movement (Sports Thought) and good physical security (physical education Thought)[12] Therefore, when building track and field course content, it must better understand the characteristics and nature of links between different sports thought, dialectical view of the relationship between health, athletics and interest between the three, to make track and field course content more reasonable and realistic.

\subsection{Discussion of Track and Field Course Construction Path and Pattern.}

Clear that the new curriculum standards in teaching suggestions in order to achieve their goals to guide the teaching content and teaching methods of choice, so when the course should give full consideration to build the effectiveness and operability of specific teaching objectives, contents and 
methods, according to a new lesson the subject of the guiding spirit of track and field course content is being rebuilt. I believe that better how to play competitive athletics courses stimulate students' interest in learning should be a system of athletics courses focus on content.

Figure 1 shows, through curriculum and development to competitive and Fitness Blending as a guide, created in line with the psychological characteristics of students taught in the form of track and field events, and create scene classroom atmosphere to stimulate student interest in learning, and ultimately to promote the health of students the goal of. In practice track and field projects in curriculum development, it is necessary to reflect the characteristics of the health and interests of track and field courses, but also as far as possible to maintain the characteristics of competitive track and field events. Lectures will be track and field events, forms of organization, evaluation methods improved by increasing the movement of technology and sports performance to maximize stimulate student participation, interest in learning and enthusiasm.

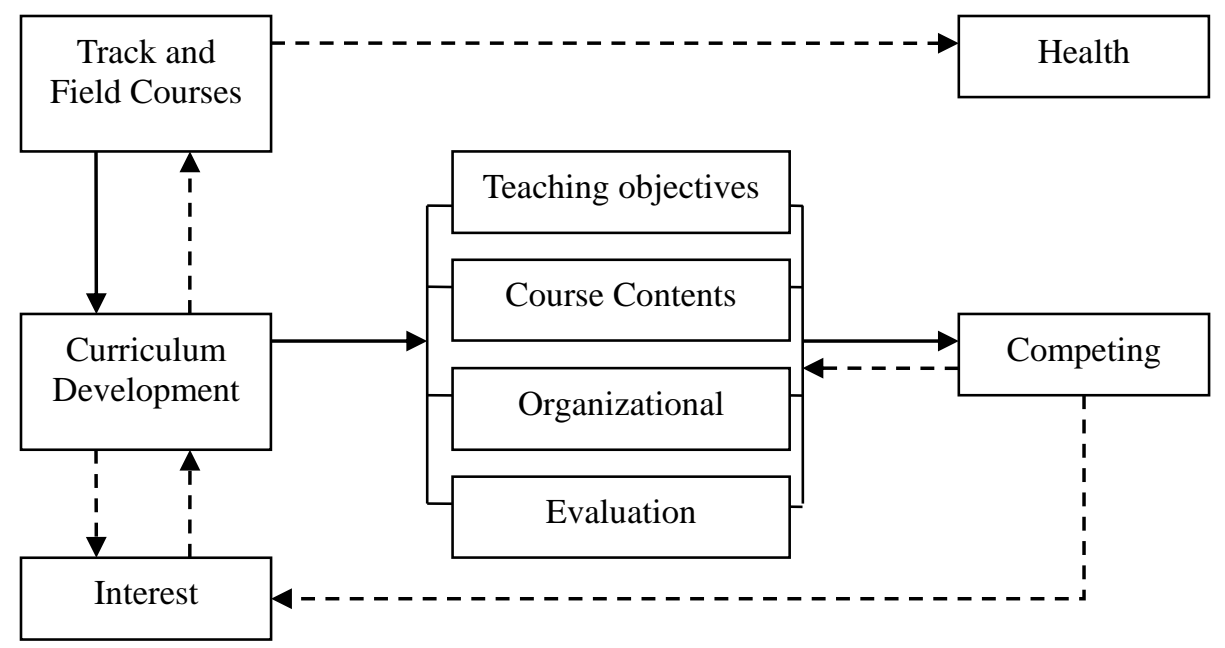

Figure 1Track and Field Curriculum Development

\section{Summary}

The new curriculum standards in the "Track and Field" named significance is to broaden our horizons, changing the uniform "Olympic project" of teaching practice, the track and field athletics, entertainment and fitness of integration, materials technology, the game of athletics to do so in line with students 'psychological characteristics, to better stimulate students' interest in learning, so as to achieve the purpose of promoting the health of students [13]. But by the "Happy Sport" and "success sports", the new curriculum standards' interest and people-centered teaching philosophy narrow understanding has led many PE teachers stage of sports teaching biological outlook to be negative, no longer pay attention to whether the exercise load well-organized, blindly cater to students' interest, leading to physical education classes into the game[14]. This is also one of the main reasons in recent years, our students physical decline. Therefore, in the choice of track and field course content, first consider whether the content is beneficial to the health of students, and the content modified to comply with reasonable psychological characteristics of students, promote students' physical and mental health will be an important building as Track and Field Course Content standard.

\section{Acknowledgements}

This work was financially supported "2015 Yulin Municipal Science and Technology Bureau Project (2015CYX_07)" 


\section{References}

[1] Cao Bo. Athletics Reform and Development [D].Jiangsu: Yangzhou University, 2004.

[2] Institute of curriculum materials.20 century Chinese curriculum criterion syllabus sports compilation volume [M].Beijing: People's Education Press, 2001: 832.

[3] Chen Xian, Xu Ping. Junior high school track and field sports curriculum textbook analysis [J].Yangzhou College of Education, 2000,23 (1): 88-89.

[4] Guo Jianlong, Wan Bing Jun, Li Shan and other theoretical construct. Primary and Secondary Schools Track and Field Curriculum Development and application [J].Xi'an Institute of Physical Education, 2007, 24 (1): 110-112.

[5] Shi Wen jiang. High school track and field teaching reform in curriculum development and environment Outlet junior track and field sports curriculum textbook analysis [J].Yangzhou College of Education, 2005,19 (5): 22-23.

[6] High self-Jun, Qin Aihua, Xu Yan. Sports and Health Course in Competitive Further Study [J].Hubei Sports Science 2006, 25 (4): 389.

[7] Chen Zuo Song, Liu Ji. New requirements to implement the new physical education curriculum for PE Teachers [J].Beijing University Hugh education, 2004, 7 (3): 370-374.

[8] Song Yabing. Health and Physical Education in Guangdong Province within the passenger system evaluation [J].Physical Education, 2003, 10 (6): 94-96.

[9] Zhong Qiquan, Liu Ji. Pedagogy - Physical Education and Health Curriculum [M]. Hangzhou: Zhejiang University Press. 2003: 41.

[10] Ministry of Education. "Sports and Health" curriculum standards [Z]. Beijing: People's Sports Publishing House .2000, 9-10.

[11] Qu Jie.process of reflection problem [J].Modern and Contemporary Chinese School Sports Thought of Sports and Science, 2005, 26 (4): 72.

[12] Chen Qi, Lu Changfen. Sports Value in New Period and sports essence, function and purpose of [J].Physical Education, 2006,13 (02): 3.

[13] LIAO Zhi Jin. Opportunities and Challenges of track and field teaching under the new subject [J].Physical Education, 2004, (5): 6-7.

[14] Yan Jinlan. Development Process and Trend of Chinese school sports thinking [J].Physical Education, 2003, 10 (5): 139. 